\title{
Apuntes sobre el Período Intermedio Tardío y la presencia inca en la cuenca alta del río Ricrán, sierra central del Perú
}

Manuel F. Perales M. ${ }^{1}$

\section{RESUMEN}

Se presentan evidencias arqueológicas inca registradas en la sección superior del valle de Ricrán, sierra central del Perú. Tras revisar la información correspondiente al Período Intermedio Tardio, se evalúa el carácter de la ocupación incaica en la zona a partir del análisis de los cambios en el patrón de asentamiento y de la presencia de edificios de probable inspiración inca y alfarería estatal en las aldeas locales. Tomando en cuenta las terrazas de cultivo, los restos de caminos y un posible sitio ceremonial asociado a la montaña de Apohuayhuay, a pesar a la ausencia de instalaciones administrativas y de almacenaje, se propone la integración del valle a los centros provinciales de Hatun Xauxa y Tarmatambo como un núcleo de producción de bienes para el Imperio y como residencia de una huaca regional.

Palabras claves: Andes Centrales - valle de Ricrán - Inca Provincial - arquitectura inca - patrón de asentamiento - montaña de Apohuayhuay - frontera étnica - élite local - centro de producción.

\begin{abstract}
Archaeological data obtained from Inca sites located in the upper Ricran valley (central sierra of Peru) is considered against other evidence from the Late Intermediate Period. This leads us to evaluate and characterize regional inca occupation through an analysis of the changes in settlement patterns, of the buildings of probable inca inspiration, and of State pottery in local villages. Agricultural terraces, remains of roads and what possibly constitutes a ceremonial site linked to the sacred mountain of Apohuayhuay nearby, suggests this area was integrated to the provincial centers of Hatun Xauxa and Tarmatambo, a production center of different goods for the Empire and as residence of a regional deity or huaca.
\end{abstract}

Key words: Central Andes - Ricran valley - Provincial Inca - inca architecture - settlement pattern Apohuayhuay mountain - ethnic frontier - local elite production center.

Recibido: marzo 2004. Manuscrito revisado aceptado: enero 2005.

1 Museo Arqueológico “Julio Espejo Núñez” de Jauja. Jirón Panamá 1842-1844, El Tambo-Huancayo, PERU. Email: apuwayway@hotmail.com

\section{Introducción}

En la sierra central peruana buena parte de las investigaciones arqueológicas más recientes acerca del impacto de la ocupación inca sobre las sociedades locales se han concentrado hacia el área nuclear de Jauja en el extremo norte del valle del Mantaro. ${ }^{2}$ Gracias a estos trabajos, sabemos que durante el Horizonte Tardío se produjo una interesante movilización y redistribución de la población local, con el consiguiente abandono de los grandes asentamientos nucleados localizados en las cumbres de cerros elevados, para dar lugar a la formación de un sinnúmero de aldeas pequeñas y dispersas, no fortificadas y localizadas en puntos de fácil acceso cerca del fondo del valle y colindantes a las áreas donde se encontraban mejores tierras de cultivo (LeBlanc 1981; Hastorf 2001). Ello significó, además, el traslado de los núcleos de poder desde los centros regionales de Hatunmarca y Tunanmarca hacia Hatun Xauxa, la capital provincial inca en el valle del Mantaro. Tanto las evidencias arqueológicas como etnohistóricas indican que ciertos sectores de la élite local fueron incorporados dentro del aparato estatal del Tawantinsuyu, en un ambiente de alianzas políticas desarrolladas con la finalidad de tomar el control de la mano de obra y la producción de una serie de bienes para el consumo estatal. Esto provocó cambios en la naturaleza de algunas actividades desarrolladas en contextos domésticos, como producción de ropa y chicha, alterando las jerarquías de poder y estatus preexistentes mediante la integración de ciertos segmentos de las élites conquistadas a su esfera (D'Altroy 1992).

Sin embargo, aún no se dispone de información suficiente para entender las estrategias desplegadas por los incas para conquistar las diversas re-

\footnotetext{
2 Otros investigadores vienen concentrando sus esfuerzos hacia las regiones de Tarma y el altiplano de Junín (Matos 1994, 1997; Matos et al. 1996).
} 
giones que se localizan alrededor del valle del Mantaro, particularmente hacia el oriente, donde las reducciones de indígenas formadas en el siglo XVI fueron consideradas desde sus inicios como pueblos "sujetos" a los del valle (Vega 1881 [1582]). La presencia de restos de antiguos caminos, de muy posible data prehispánica, que conectaban la zona de Jauja con los pequeños valles y la ceja de montaña adyacentes, confirmaría la existencia de una intensa interacción entre las poblaciones del Mantaro y sus vecinas.

Con el objetivo de contribuir al desarrollo de esta problemática, iniciamos en 1999 un reconocimiento intensivo en la sección superior del valle de Ricrán, al norte de Jauja. Este sector se seleccionó debido a su posición estratégica como nudo de caminos tradicionales que unen a diversas comunidades de Jauja, Tarma y la ceja de montaña de Tambillo y Monobamba, además de su fama como centro productor de tubérculos de altura a nivel regional. Durante la ejecución de estos trabajos se identificaron en varios asentamientos locales restos materiales que evidenciaban en algún modo la presencia de los incas, entre los que destaca un sitio con posible arquitectura estatal asociado a la montaña sagrada de Apohuayhuay.

El presente trabajo tiene como finalidad presentar estas evidencias junto a algunas ideas que venimos desarrollando en torno al carácter de la presencia inca en el alto Ricrán.

\section{La región en estudio}

El valle de Ricrán se localiza en las secciones norcentral de la actual provincia de Jauja y suroriental de la provincia de Tarma, ambas pertenecientes al departamento de Junín, sierra central del Perú, entre los $11^{\circ} 20^{\prime}$ y $11^{\circ} 39^{\prime}$ de Lat. Sur y $\operatorname{los} 75^{\circ} 25^{\prime}$ y $75^{\circ} 40^{\prime}$ de Long. Oeste. El colector hídrico principal es el río del mismo nombre, el cual es uno de los principales afluentes del río Tarma. Nace de los desagües de las lagunas de Suerococha, Yanacocha y Totoracocha localizadas a $4 \mathrm{~km}$ al sureste de la localidad de Jatun Ucu, a $4430 \mathrm{~m} . \mathrm{snm}$. Desde ese punto corre en dirección noroeste a través de una cuenca morrénica hasta las inmediaciones del paraje de Auquispuquio, donde el valle se encajona entre dos cadenas montañosas de fuertes pendientes y de naturaleza litológica de tipo sedimentario y metamórfico, en medio de las cuales se localiza el pueblo de Santa Margarita de Ricrán (3675 m.snm), capital del distrito del mismo nombre, provincia de Jauja. Aguas abajo, el cauce del río se profundiza conforme avanza hacia el norte para desembocar finalmente en el río Tarma a la altura del pueblo de Palca, a 2738 m.snm, luego de pasar por las poblaciones de Congas Antacucho (donde recibe las aguas del río Shururuyoc por su margen izquierdo), Maco, Yuracmayo, Yaroca y Huaripampa, donde el río Tapo desemboca por su margen izquierdo. El área de nuestra investigación se circunscribe a la sección alta de la cuenca del río Ricrán, desde la quebrada de ChúlecJanchiscocha hasta el punto de desembocadura del río Shururuyoc en el Ricrán, muy cerca del pueblo de Congas Antacucho (Figura 1). En este territorio destaca la cadena montañosa de Apohuayhuay localizada al este, con picos como el Apohuayhuay (5106 m.snm), Chontahuayhuay (4927 m.snm) y Shullcahuayhuay (4830 m.snm) que hasta hace poco tiempo se encontraban cubiertos con nieves perennes y de cuyos deshielos se forman abundantes lagunas y cursos de agua que alimentan el caudal del río Ricrán. Por su parte, la cadena que encierra al valle por el oeste es más baja, carente de fuentes de agua y, por lo tanto, de buenos pastizales, con cumbres que no sobrepasan los 4350 m.snm.

De acuerdo a las clasificaciones existentes (Tosi 1960) se pueden identificar en este territorio diversas zonas de vida natural distribuidas a lo largo de tres pisos ecológicos claramente diferenciados: cordillera, puna y suni/quechua (Pulgar 1967). La cordillera se refiere a los picos montañosos de la cadena de Apohuayhuay que se localizan al este del valle, y que alcanzan altitudes superiores a los $4800 \mathrm{~m} . \mathrm{snm}$ en los que se representa claramente la Formación nival, con relictos de nieves perpetuas y vegetación prácticamente inexistente (Tosi 1960). Dentro de la puna se incluyen los pastizales aprovechados para la ganadería que se elevan por encima de los 4000 m.snm y que se concentran hacia las nacientes del río Ricrán y las partes altas de las laderas que encierran al valle. Esta zona de vida es denominada por Tosi "Páramo muy húmedo subalpino" y comprende, además, los territorios ondulantes localizados hacia la base de los picos cordilleranos del oriente. El piso suni/quechua, por su parte, se concentra principalmente hacia los fondos estrechos del valle y las quebradas laterales (3500-3800 m.snm), así como en los sectores inferiores de las 
laderas, hasta una altitud aproximada de 3900 m.snm, encontrándose aquí la zona de vida denominada "Bosque húmedo montano" (Tosi 1960), foco principal de la actividad agrícola orientada principalmente a la producción de tubérculos (Solanum tuberosum o andigeum, Oxalis tuberosa, Tropaeolum tuberosum), quinua (Chenopodium quinoa) y cereales europeos (p.e., Hordeum sp.).

\section{Consideraciones etnohistóricas}

Ninguno de los cronistas que visitaron la sierra central del Perú en los primeros años de la conquista hacen referencia al valle de Ricrán o a sus poblaciones prehispánicas, situación que se repite en el caso de los documentos administrativos tempranos concernientes a la región, que han sido publicados como los memoriales de los curacas de Jauja elevados en el siglo XVI al rey de España (Espinoza 1971) y los interrogatorios realizados por Andrés de Vega en 1582 a los señores naturales del valle del Mantaro. En estos sí se menciona la prematura existencia de los pueblos de Monobamba y Uchubamba, localizados en la ceja de selva al este de Ricrán, como reducciones de indígenas pertenecientes a las parcialidades de Hatun Xauxa y Lurinhuanca, respectivamente (Vega 1881 [1582]).

Las únicas referencias específicas sobre Ricrán publicadas hasta el momento son bastante tardías y corresponden a la demarcación eclesiástica de la provincia de Jauja, hacia mediados del siglo XVIII, donde el pueblo de Ricrán figura como un anexo del curato de Jauja (Espinoza 1973). Por su parte, Arellano (1988) ha analizado exhaustivamente un importante corpus de documentos coloniales que versan sobre las antiguas haciendas de Apaicancha, Yuracmayo, Ayas, Maco y Apaicanchilla, ubicadas en el valle del río Shururuyoc, demostrando que estuvieron bajo la jurisdicción y administración de los curacas de Tarma hasta los siglos XVII y XVIII, cuando las perdieron a raíz de donaciones, embargos, ventas forzadas e, inclusive, invasiones como la que sufrió la hacienda Yuracmayo a manos de indígenas procedentes de Ricrán (Arellano 1988: 32).

Para culminar este punto, debemos indicar que tenemos conocimiento de la existencia de documentos inéditos del siglo XVIII referentes a procesos judiciales habidos por la posesión de pastizales entre algunos españoles y los indígenas del ayllo Vico Huarancayo ${ }^{3}$ de Ricrán. En estos textos, se señalan los límites del mencionado ayllo, coincidiendo en gran medida con la información recuperada por Arellano (1988). Sin duda, un estudio detallado de estas fuentes será fundamental para la comprensión de la historia de las sociedades prehispánicas tardías de la zona y el impacto del régimen colonial sobre ellas.

\section{Ocupaciones del Período Intermedio Tardío en la cuenca alta del río Ricrán}

\section{La base de información}

Los reconocimientos arqueológicos en la cuenca alta del río Ricrán fueron iniciados en junio de 1999, con el objetivo de estudiar los patrones de asentamiento en la zona y sus cambios a través del tiempo, de manera particular durante el Período Intermedio Tardío (900/1000-1460 DC) y la ocupación inca. Debido a la accidentada configuración del terreno, se optó por desarrollar todo el reconocimiento a pie, con la ayuda de fotografías aéreas y mapas a escala 1: 100000 y 1: 25000 elaborados por el Instituto Geográfico Nacional y el Ministerio de Agricultura del Perú. El área reconocida comprendió entre la localidad de ChúlecJanchiscocha por el sur, a $4200 \mathrm{~m} . \mathrm{snm}$, hasta el pueblo de Congas Antacucho por el norte, ubicado a $3550 \mathrm{~m} . \mathrm{snm}$, cubriendo desde el fondo del valle hasta los extensos pajonales y cumbres localizadas especialmente hacia el este, entre los 4200 y 4500 m.snm. La ubicación cronológica de los sitios registrados se determinó mediante el análisis de la cerámica superficial asociada, información que luego fue comparada con las secuencias cronológicas alfareras disponibles para las regiones de Jauja (Browman 1970; Costin 1986; Earle et al. 1987) y Tarma (Parsons et al. 2000). Debido a limitaciones financieras las excavaciones se reservaron para futuras temporadas de trabajo de campo.

El registro y clasificación de los sitios fue un punto crítico en nuestras investigaciones, debido a que el valle de Ricrán es casi desconocido arqueológicamente. Por ello, se ha preparado una tipología preliminar que considera: a) asentamientos; b)

Estos documentos obran en manos de la Comunidad Campesina de Ricrán y forman parte de los documentos con los cuales se obtuvo su reconocimiento oficial por parte del Estado peruano en 1935. 
cementerios, y c) elementos aislados. Estas categorías intentan recoger los criterios empleados por Parsons y colaboradores $(1997,2000)$ en su estudio de los patrones de asentamiento en las regiones de Tarma y Junín y que se orientó al análisis de las formas de organización sociopolítica en épocas prehispánicas y sus cambios en el tiempo. Al igual que Parsons y colaboradores (2000: 90) también consideramos que no sería adecuado, al menos por ahora, emplear la tipología de sitios de Earle y colaboradores (1987) elaborada para la región de Jauja, debido principalmente a que en Ricrán: 1) los sitios son generalmente mucho más pequeños que aquellos de la región de Jauja; 2) al igual que en Tarma, es difícil identificar con total certeza restos de arquitectura y espacios de carácter público en los asentamientos, y 3) gran parte del territorio estudiado está comprendido dentro de la zona de puna, en tanto que en Jauja los reconocimientos del Proyecto Alto Mantaro cubrieron principalmente los valles de Yanamarca y Mantaro, en los pisos ecológicos quechua y suni.

\section{Asentamientos}

A modo de aclaración previa debemos señalar que la carencia de excavaciones no nos permite discernir eventuales cambios que podrían haber ocurrido en el patrón de asentamiento en Ricrán durante el Intermedio Tardío, como sí se ha logrado para el área nuclear de Jauja (Earle et al. 1987; Hastorf et al. 1989; D'Altroy 1992, 2001a), donde se han definido las fases Wanka I (1000-1350 DC) y Wanka II (1350-1450 DC). En relación al Horizonte Tardío destaca en esta parte de la sierra central la aparente continuidad en la producción de determinados tipos alfareros locales como Mantaro Base Clara y la presencia de cerámica inca en varios asentamientos que no exhiben cambios sustanciales en su arquitectura y organización interna. Por lo expuesto resulta bastante problemático cualquier intento por identificar la ubicación cronológica exacta de muchos sitios a partir de un reconocimiento de superficie. Esta dificultad, ya señalada por Earle y colaboradores (1988) y Parsons y colaboradores (2000), también la encontramos en el alto Ricrán, razón por la cual en esta ocasión no intentaremos mayores diferenciaciones cronológicas entre y dentro de los dos últimos períodos de la secuencia prehispánica, limitándonos, en el caso de los sitios con restos materiales inca en superficie o vinculados a esta cultura, a señalar la posibilidad de su ocupación o reocupación durante el Horizonte Tardío.
Los asentamientos tardíos en el alto Ricrán se localizan en partes elevadas y alejadas del fondo del valle como cumbres de estribaciones y crestas montañosas desde donde se disponía de un excelente dominio del paisaje. En su totalidad, estos sitios están constituidos por concentraciones de edificios circulares de un solo nivel levantados a base de piedra asentada en argamasa de barro, ${ }^{4}$ con diámetros de $3 \mathrm{~m}$ a $5 \mathrm{~m}$. Estos están distribuidos alrededor de espacios abiertos a modo de patios, formados por terrazas artificiales preparadas para atenuar la pendiente del terreno y habilitar áreas para la construcción, característica que también se ha observado en los asentamientos locales tardíos de Jauja (Earle et al. 1987) en los cuales, a diferencia de los sitios de Ricrán, se han documentado espacios centrales abiertos o "plazas" asociadas a edificios de muy posible carácter público (Bonnier 1997; DeMarrais 2001).

De acuerdo a su emplazamiento ecológico y elementos asociados (terrazas de cultivo y corrales), estamos agrupando a los sitios tardíos del alto Ricrán en dos categorías principales (ver Figura 1), asentamientos de ganaderos y asentamientos de agricultores, al interior de las cuales se propone una clasificación en base al tamaño, densidad de los edificios y la posible importancia sociopolítica de los sitios, siguiendo a grandes rasgos los criterios definidos por Parsons y colaboradores (2000). De este modo tenemos (ver Tabla 1):

1) Asentamientos de ganaderos. Sitios localizados sobre cumbres elevadas que dominan las cadenas de montañas que encierran al valle por el este y oeste, generalmente emplazados a más de 4000 o 4200 m.snm en el piso puna y con fácil acceso a pastizales. Presentan grandes corrales de piedra asociados y muros perimétricos alternados muchas veces con zanjas. Su extensión varía entre 14 ha y 1.5 ha, y de acuerdo a su tamaño pueden subdividirse en:

Clase A: 10-14 hectáreas

Clase B: 7-10 hectáreas

Clase C: 5-7 hectáreas

Clase D: 3-5 hectáreas

Clase E: 1.5-3 hectáreas

4 Los muros de estos edificios presentan doble hilera de piedras y están ligeramente inclinados hacia el interior. Su espesor promedio es de $30 \mathrm{~cm}$. 


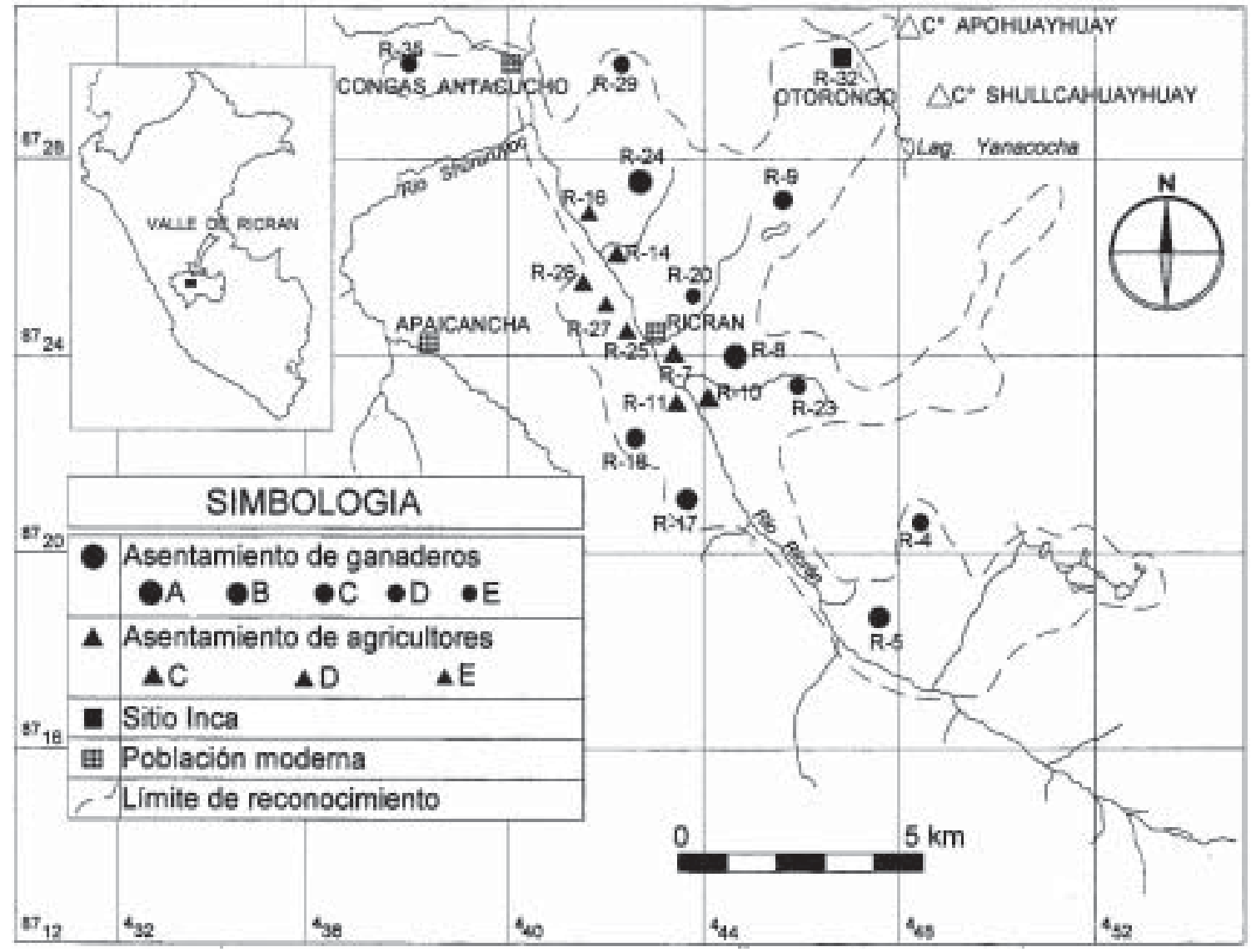

Figura 1. Ubicación de los asentamientos tardíos registrados en el alto Ricrán y del sitio R-32, Otorongo.

\begin{tabular}{|c|c|c|c|}
\hline $\mathrm{N}^{0}$ sitio / Nombre & Altitud (m.snm) & Coordenadas UTM & Clasificación propuesta \\
\hline R-4, Malca Malca & 4550 & $448270 \mathrm{E} / 8720750 \mathrm{~N}$ & Asent. ganaderos, Clase D \\
\hline R-5, Culimalca & 4360 & $447720 \mathrm{E} / 8718750 \mathrm{~N}$ & Asent. ganaderos, Clase B \\
\hline R-7, Chanchanloma & 3870 & $443720 \mathrm{E} / 8724060 \mathrm{~N}$ & Asent. agricultores, Clase C \\
\hline R-8, Huacrash & 4230 & $444700 \mathrm{E} / 8724330 \mathrm{~N}$ & Asent. ganaderos, Clase A \\
\hline R-9, Jaygucuchu & 4290 & $445700 \mathrm{E} / 8727170 \mathrm{~N}$ & Asent. ganaderos, Clase C \\
\hline R-10, Ricramarca & 3860 & $444000 \mathrm{E} / 8723350 \mathrm{~N}$ & Asent. agricultores, Clase C \\
\hline R-11, Oyuncuy & 3820 & $443560 \mathrm{E} / 8723340 \mathrm{~N}$ & Asent. agricultores, Clase D \\
\hline R-14, Tantarnioc & 3804 & $442300 \mathrm{E} / 8726050 \mathrm{~N}$ & Asent. agricultores, Clase D \\
\hline R-16, Cahuayacmarca & 3795 & $441700 \mathrm{E} / 8727100 \mathrm{~N}$ & Asent. agricultores, Clase E \\
\hline R-17, Pariamarca & 4280 & $443550 \mathrm{E} / 8721220 \mathrm{~N}$ & Asent. ganaderos, Clase B \\
\hline R-18, Huajá & 4345 & $442700 \mathrm{E} / 8722550 \mathrm{~N}$ & Asent. ganaderos, Clase C \\
\hline R-20, Uyash & 4233 & $443680 \mathrm{E} / 8725390 \mathrm{~N}$ & Asent. ganaderos, Clase E \\
\hline R-23, Huacacorral & 4240 & $445880 \mathrm{E} / 8723100 \mathrm{~N}$ & Asent. ganaderos, Clase D \\
\hline R-24, Huarancayo & 4396 & $442760 \mathrm{E} / 8727760 \mathrm{~N}$ & Asent. ganaderos, Clase A \\
\hline R-25, Cashamarca & 3807 & $442360 \mathrm{E} / 8724420 \mathrm{~N}$ & Asent. agricultores, Clase D \\
\hline R-27, Sillajasha & 3926 & $441750 \mathrm{E} / 8725000 \mathrm{~N}$ & Asent. agricultores, Clase E \\
\hline R-28, Jarapunco & 3778 & $441620 \mathrm{E} / 8725550 \mathrm{~N}$ & Asent. agricultores, Clase D \\
\hline R-29, Taurishnioc & 4170 & $442200 \mathrm{E} / 8729820 \mathrm{~N}$ & Asent. ganaderos, Clase D \\
\hline R-35, Huaychaomarca* & 4250 & $437880 \mathrm{E} / 8729650 \mathrm{~N}$ & Asent. ganaderos, Clase D \\
\hline
\end{tabular}

Tabla 1. Asentamientos del Intermedio Tardío/Horizonte Tardío registrados en el alto Ricrán.

* Sitio $n^{\circ} 250$ en el registro de Parsons y colaboradores (2000: 383). 
2) Asentamientos de agricultores. Sitios asociados a terrazas de cultivo, localizados entre los 3800 y $4000 \mathrm{~m} . \mathrm{snm}$, en la cima de estribaciones cordilleranas que descienden hacia el fondo del valle. Estos asentamientos, emplazados en el piso suni y con fácil acceso a las zonas agrícolas de los límites superiores del piso quechua, carecen de muros perimétricos, aunque sí presentan zanjas en algunos casos. Su extensión oscila entre las 3.5 ha y 1.2 ha, siendo notablemente más pequeños que los asentamientos de ganaderos. Nuevamente nuestros datos confirman la clasificación con la de Parsons y colaboradores $(2000)^{5}$ y, por lo tanto, tenemos sólo las siguientes clases:

Clase C: 2.7-3.5 hectáreas

Clase D: 2.2-2.7 hectáreas

Clase E: 1.2-2.2 hectáreas

En todos estos asentamientos la unidad arquitectónica básica es el denominado "grupo de patio" (DeMarrais 2001) conformado por una o más estructuras circulares dispuestas alrededor de un espacio central abierto. Estos conjuntos también han sido llamados "unidades alveolares" (Lavallée y Julien 1983) y de acuerdo a las investigaciones arqueológicas (LeBlanc 1981; Earle et al. 1987) sirvieron como residencia de unidades domésticas o familiares.

En Ricrán, sin duda, son los "asentamientos de ganaderos" los que exhiben mayor complejidad en relación a su organización interna, pues, además de los conjuntos de unidades residenciales o grupos de patio, presentan una red más compleja de áreas de circulación y posibles divisiones duales o en mitades como ocurre con el sitio R-8, por ejemplo. Sin embargo, como ya indicamos antes, no hay presencia de plazas o espacios centrales de carácter público claramente definidos, y tampoco de elementos arquitectónicos producto de una la-

5 En su estudio de los patrones de asentamiento en Tarma, Parsons y colaboradores (2000) definen las diferentes clases de asentamientos, tanto de "ganaderos" como "agricultores", en función del número de unidades domésticas presentes en cada sitio. En vista que nosotros carecemos de planos detallados de gran parte de los sitios y de datos de excavación que nos permitan definir categóricamente una unidad doméstica, hemos optado por emplear principalmente el criterio del tamaño del sitio, además de rasgos arquitectónicos que denoten importancia como murallas, mayor cantidad de corrales o terrazas asociadas, tumbas, entre otros. bor corporativa, a excepción de muros perimétricos y zanjas que restringen el acceso a estos pueblos (sitios R-5, R-8, R-17, R-18, R-24, R-35), aspecto compartido con los grandes asentamientos Xauxa de la fase Wanka II del valle de Yanamarca (LeBlanc 1981; DeMarrais 2001).

Aunque todavía no hemos ejecutado un estudio minucioso de las dimensiones de las unidades residenciales y su variabilidad resulta, asimismo, evidente que la densidad de éstos es más elevada en los asentamientos de ganaderos, donde también se pueden distinguir ciertas diferencias en la calidad de la albañilería y acabado de las caras externas de los edificios y donde se hacen presentes edificios funerarios de dos tipos: 1) Edificios funerarios asociados a los muros perimétricos de los asentamientos y/o sus accesos principales; 2) Edificios funerarios asociados a grupos de patio al interior de los asentamientos (Perales 2004).

Estas edificaciones son de planta circular y están levantadas a base de piedra y argamasa de barro, presentando entre $80 \mathrm{~cm}$ y $1 \mathrm{~m}$ de diámetro, vanos pequeños y cubiertas elaboradas con lajas de piedra a modo de falsa bóveda. Algunas estructuras son semisubterráneas y en estos casos se presentan formando hileras cerca del acceso principal del asentamiento como se aprecia en los sitios R-35 y R-17. Debemos dejar en claro que este tipo de evidencias están ausentes en los "asentamientos de agricultores", aunque hemos registrado algunos edificios funerarios en abrigos rocosos en el sitio R-11, muy cerca del sector residencial del asentamiento.

Atención aparte merecen unas estructuras de planta rectangular de dos niveles levantadas con piedra asentada en barro, de aproximadamente $3 \mathrm{~m}$ de largo por $2 \mathrm{~m}$ de ancho y techumbres constituidas por lajas de piedra en falsa bóveda, las cuales se pueden apreciar en el sitio R-35 donde, pese a no ser muy abundantes, se hallan asociadas a conjuntos de construcciones circulares y reúnen las características típicas de los edificios rectangulares de dos niveles que Hastings (1987: 151) y Parsons y colaboradores $(1997,2000)$ identifican como diagnósticos de la tradición arquitectónica del alto Tarma y cuya función habría sido la de almacenaje. Nuestro sitio R-35 fue identificado por Parsons y colaboradores (2000: 383) mediante fotografías aéreas, figurando en su registro con el número $250 \mathrm{y}$ consignado como un 
asentamiento de ganaderos de Clase $\mathrm{D}$, propuesta con la que coincide nuestra clasificación.

En cuanto a la distribución de los asentamientos cabe recalcar que es notoria una mayor densidad de sitios hacia el margen oriental del valle de Ricrán, donde precisamente se encuentran la mayoría de aquellos que encabezan la jerarquía local de asentamientos (R-24, R-8 y R-5). Todos son del tipo "ganaderos" y están ubicados sobre los 4200 m.snm. Este fenómeno podría deberse en parte a la presencia en este margen de mayores extensiones de pastizales de buena calidad y de fuentes de agua de mayor caudal como manantiales, arroyos y lagunas que se alimentan de los deshielos de la cordillera de Apohuayhuay. Todo lo contrario ocurre en la cadena montañosa que separa los valles de Ricrán y Apaicancha al este, donde hay pastos más pobres, escasas fuentes de agua y suelos menos profundos y productivos.

\section{Cementerios}

En esta categoría estamos considerando a los sitios constituidos por agrupaciones de estructuras funerarias que se encuentran claramente aislados de los asentamientos (Figura 2) y que pueden ser clasificados en dos conjuntos principales, confirmando la propuesta de Parsons y colaboradores (2000) para la región de Tarma (ver Tabla 2):

Cementerio grande:más de 30 edificios funerarios. Cementerio pequeño: menos de 30 edificios funerarios.

Estos sitios se localizan principalmente en amplios abrigos y reparos ubicados casi al pie de grandes afloramientos rocosos y farellones que encajonan los cursos de los tributarios del río Ricrán que descienden por su margen derecho. Algunos se elevan a escasos $20 \mathrm{~m}$ sobre el fondo del valle (p.e., sitio R-6), aunque los sitios más importantes se encuentran en la transición entre el piso suni y la puna, en las secciones altas de las quebradas laterales (sitios R-12, R-19 y R-30). ${ }^{6}$

\footnotetext{
6 Concentraciones importantes de este tipo de cementerios se han reportado en la quebrada de Cucún o Cuncun, en el margen izquierdo del valle de Palcamayo, Tarma, donde también parecen ubicarse hacia la transición entre los pisos suni y puna (Parsons et al. 2000).
}

Los edificios presentan planta oval y circular, con diámetros internos que no sobrepasan los $60 \mathrm{~cm}$ y con muros de $20 \mathrm{~cm}$ de espesor promedio constituidos por una sola hilera de piedras asentadas en argamasa de barro y que, en muchos casos, se adosan a la pared rocosa del abrigo o reparo. $\mathrm{La}$ mayoría de estas estructuras han sido objeto de saqueos, aunque quedan todavía unas cuantas donde se pueden apreciar cubiertas elaboradas con lajas de piedra a modo de falsa bóveda, que a veces sirven como piso para un segundo nivel. Sin embargo, no se han podido documentar vanos pues al parecer éstos, de haber existido, fueron destruidos por los saqueadores para lograr forados más grandes que faciliten la extracción rápida del contenido de la tumba.

En nuestro registro destaca el sitio R-30 en cuya sección central se identificó una estructura grande de piedra y barro con planta en forma de " $D$ ", de $4.40 \mathrm{~m}$ de largo y $1.70 \mathrm{~m}$ de ancho máximo, cuyos muros presentan un espesor de $50 \mathrm{~cm}$ y se yerguen en la actualidad hasta una altura de $2 \mathrm{~m}$. En su interior, al igual que en las estructuras pequeñas, se observan restos de osamentas humanas y aunque su estado de conservación es regular, no presenta evidencias claras de vanos de ingreso. Además, los edificios circulares y ovales que se disponen a ambos lados de esta estructura mayor presentan pictografías asociadas que consisten principalmente en círculos concéntricos y líneas verticales rectas ejecutadas en color rojo ocre sobre la pared rocosa del abrigo. Otros cementerios donde se aprecia arte rupestre (pictografías) asociado, aunque menos elaborado, son los sitios R-12, R-33 y R-34.

\section{Elementos aislados}

En esta categoría consideramos a los diferentes vestigios que se hallan separados espacialmente de las otras dos categorías de sitios y que no cumplieron una función residencial o exclusivamente funeraria. Hasta el momento hemos registrado (ver Figura 2):

a) Concentraciones de corrales de piedra, principalmente en el sector de Chúlec-Janchiscocha, cerca de los sitios R-4 y R-5.

b) Concentraciones de pozas de piedra hoy abandonadas en la quebrada Llamapinta, similares a las pozas que etnográficamente hemos documen- 


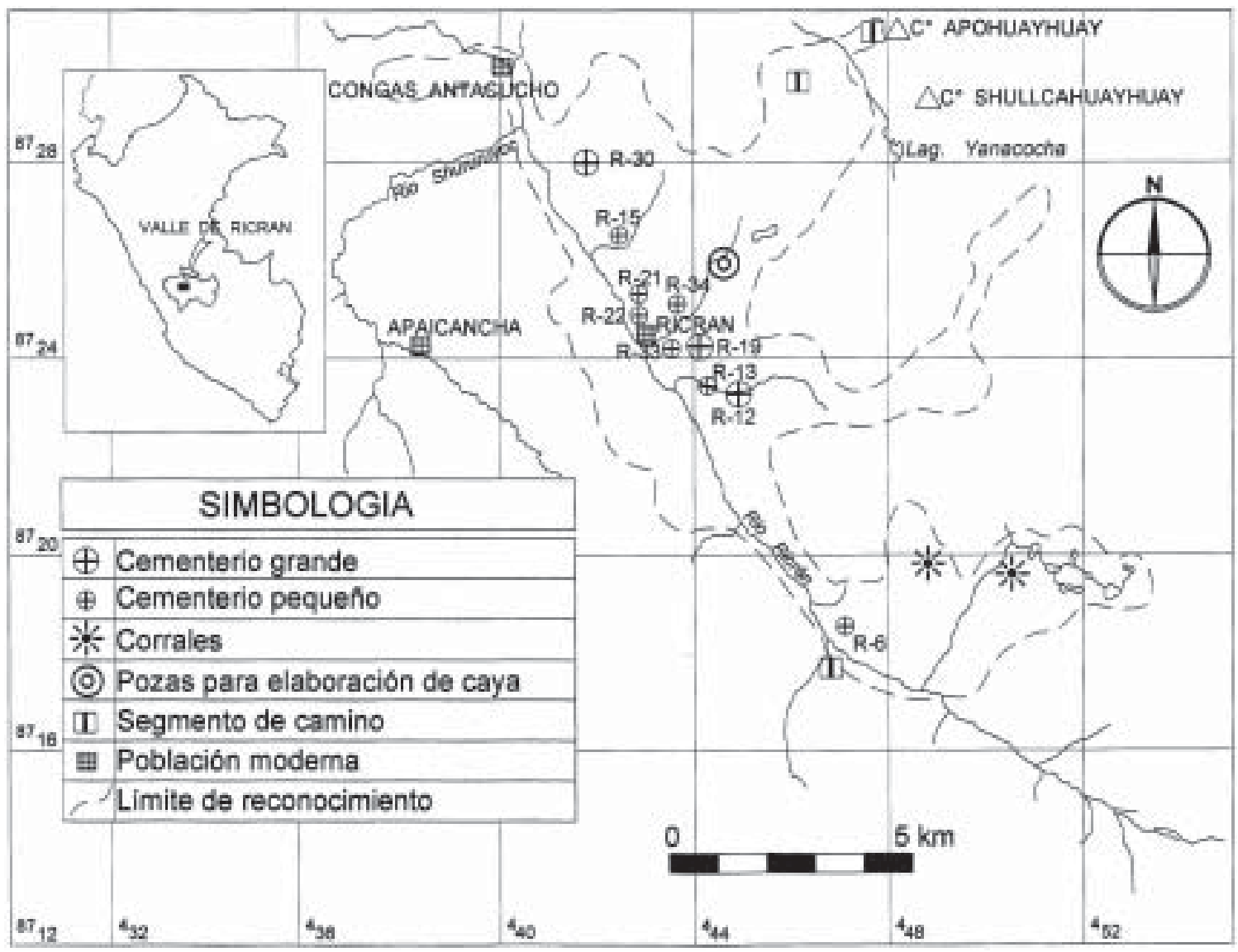

Figura 2. Ubicación de los cementerios tardíos y elementos aislados registrados en el alto Ricrán.

\begin{tabular}{|c|c|c|c|}
\hline $\mathbf{N}^{0}$ sitio / Nombre & Altitud (m.snm) & Coordenadas UTM & Clasificación propuesta \\
\hline R-6, Auquispuquio & 3980 & $447370 \mathrm{E} / 8717950 \mathrm{~N}$ & Cementerio pequeño \\
\hline R-12, Campanayoc* & 4040 & $445700 \mathrm{E} / 8727170 \mathrm{~N}$ & Cementerio grande \\
\hline $\mathrm{R}-13, \mathrm{~s} / \mathrm{n}$ & 3985 & $445550 \mathrm{E} / 8724000 \mathrm{~N}$ & Cementerio pequeño \\
\hline R-15, Huacrapuquio & 3780 & $442310 \mathrm{E} / 8726250 \mathrm{~N}$ & Cementerio pequeño \\
\hline R-19, Ayamachay & 3955 & $444320 \mathrm{E} / 8725080 \mathrm{~N}$ & Cementerio grande \\
\hline R-21, Cruzpata & 3750 & $443190 \mathrm{E} / 8724580 \mathrm{~N}$ & Cementerio pequeño \\
\hline $\mathrm{R}-22, \mathrm{~s} / \mathrm{n}$ & 4005 & $445460 \mathrm{E} / 8723180 \mathrm{~N}$ & Cementerio pequeño \\
\hline R-30, Huarimachay* & 3907 & $441750 \mathrm{E} / 8728500 \mathrm{~N}$ & Cementerio grande \\
\hline R-33,Huachuamachay* & 3690 & $443400 \mathrm{E} / 8724370 \mathrm{~N}$ & Cementerio pequeño \\
\hline R-34, Jallumachay* & 3702 & $443530 \mathrm{E} / 8724380 \mathrm{~N}$ & Cementerio pequeño \\
\hline
\end{tabular}

Tabla 2. Cementerios del Intermedio Tardío/Horizonte Tardío registrados en el alto Ricrán.

* Sitios con arte rupestre (pictografías) asociado.

tado en la zona y que son empleadas para la elaboración de la caya u oca deshidratada (Oxalis tuberosa).

c) Segmentos de caminos antiguos, posiblemente prehispánicos, en las quebradas de Cachirumi y Cargadero. Estos caminos presentan restos de empedrados y ductos para drenaje. En el caso de la quebrada Cargadero, el camino pasa muy cerca del sitio R-32, al pie del nevado de Apohuayhuay.

\section{Cerámica}

Existen distintas clasificaciones y secuencias alfareras elaboradas desde la década de 1960 para la sierra central del Perú (Lavallée 1967; Lumbre- 
ras 1960) y particularmente para el valle del Mantaro (Browman 1970) y la región de Jauja (Costin 1986; Earle et al. 1987; Hastorf et al. 1989; D'Altroy 1992). No obstante sus problemas de orden cronológico, constituyen herramientas fundamentales para ubicar provisionalmente a los tipos alfareros del alto Ricrán dentro del contexto regional. Aunque están pendientes análisis exhaustivos, podemos adelantar que el componente cerámico más característico asociado a los sitios reportados es un género de pasta de textura regular a fina, con colores que varían entre naranja, rosado claro y ante, con inclusiones de mica, cuarzo y partículas de roca con superficies alisadas que exhiben por lo general empleo de engobe y decoración consistente en bandas irregulares rectas y ondulantes de color marrón, gris y eventualmente púrpura, siendo las formas preferidas ollas, jarros y platos. Siguiendo los criterios de otros investigadores (Lumbreras 1957, 1960; Matos 1959; Costin 1986, 1986-87, 2001) se podría vincular a este conjunto con el tipo Mantaro Base Clara que cronológicamente corresponde al Intermedio Tardío y cuya producción continuó durante el dominio inca. En cantidades menores se encuentran fragmentos de cerámica que corresponderían a los tipos Wanka Rojo, Engobado Crema y Autoengobado Micáceo (Costin 1986, 1986-87, 2001).

En los sitios R-24, R-29 y R-35, localizados en el extremo norte del territorio cubierto por nuestros reconocimientos, se observa en las colecciones de superficie la presencia de fragmentos de cerámica de pasta regular a fina, cocción reductora combinada con ventilación en ambientes oxidantes al final del proceso, de color básicamente ante o bayo, con partículas de cuarzo, roca y algo de mica y que exhiben superficies bien alisadas, con incierto uso de engobe pero con característica decoración pintada consistente en bandas verticales y horizontales de color rojo. Esta cerámica, cuyas formas favoritas son cuencos y algunos jarros, parece vincularse con el tipo San Blas Rojo sobre Ante, propio de las regiones de Tarma y Junín (Hastings 1985, 1987; Parsons et al. 2000).

\section{Evidencias sobre fronteras étnicas}

La documentación etnohistórica disponible nos permite tener una visión general del panorama étnico de la sierra central peruana antes de la llegada de los incas (p.e., Estete 1946 [1533]; Cieza de León 1946 [1553]; Vega 1881 [1582]), aspecto que ha empezado a ser evaluado desde una pers- pectiva arqueológica (Hastings 1987; Bonnier 1997; Parsons et al. 1997, 2000; Perales 2003 Msa; Perales y Rodríguez 2003). De interés en la presente oportunidad son los grupos étnicos Xauxa y Tarama que ocupaban las regiones de Jauja y Tarma, respectivamente. Los Xauxa, cuyo núcleo se encontraba en el valle de Yanamarca (LeBlanc 1981; Earle et al. 1987; D’Altroy 1992, 2001a), eran quizás la entidad étnica que mayor complejidad estaba alcanzando durante el Intermedio Tardío como se desprende de las dimensiones impresionantes de sus principales asentamientos y en la presencia clara de espacios públicos centrales en éstos (Bonnier 1997; DeMarrais 2001). Su cultura material se distingue principalmente en el campo de la arquitectura y la cerámica. Sobre la primera destaca el uso exclusivo de la planta circular con edificios residenciales de un solo nivel. Los tipos alfareros vinculados con este grupo son Mantaro Base Clara, Wanka Rojo, Autoengobado Micáceo, Engobado Crema y, en menor cantidad, alfarería con temperante de andesita (Costin 1986, 2001).

Los Tarama aparecen tradicionalmente vinculados a los Chinchaycocha que ocupaban gran parte del altiplano de Junín, e inclusive durante el régimen inca e inicios de la Colonia formaban una misma unidad administrativa (Arellano 1988; Hastings 1987; Matos et al. 1996). Desde la perspectiva arqueológica también existen algunas relaciones entre ambos grupos étnicos como el uso común de la cerámica San Blas Rojo sobre Ante (Hastings 1987; Parsons et al. 2000), aunque los asentamientos Tarama se diferencian por la presencia de los edificios de planta rectangular de dos niveles que ya hemos referido antes como característicos de la tradición arquitectónica del alto Tarma (Parsons et al. 2000).

En el valle de Ricrán hemos detectado cambios en la cultura material de sus poblaciones prehispánicas tardías (principalmente arquitectura y cerámica) que creemos pueden ser evidencias de la existencia de un territorio fronterizo entre grupos ligados a las etnicidades Xauxa y Tarama (Figura 3). Tal como se ha indicado en los acápites anteriores, en los sitios de la sección septentrional de nuestra zona de estudio, hacia los actuales pueblos de Congas Antacucho y Maco, se observan vestigios materiales que podrían relacionarse con los Tarama, principalmente edificios rectangulares de dos niveles (sitio R-35) y cerámica San Blas Rojo sobre Ante (sitios R-24, 


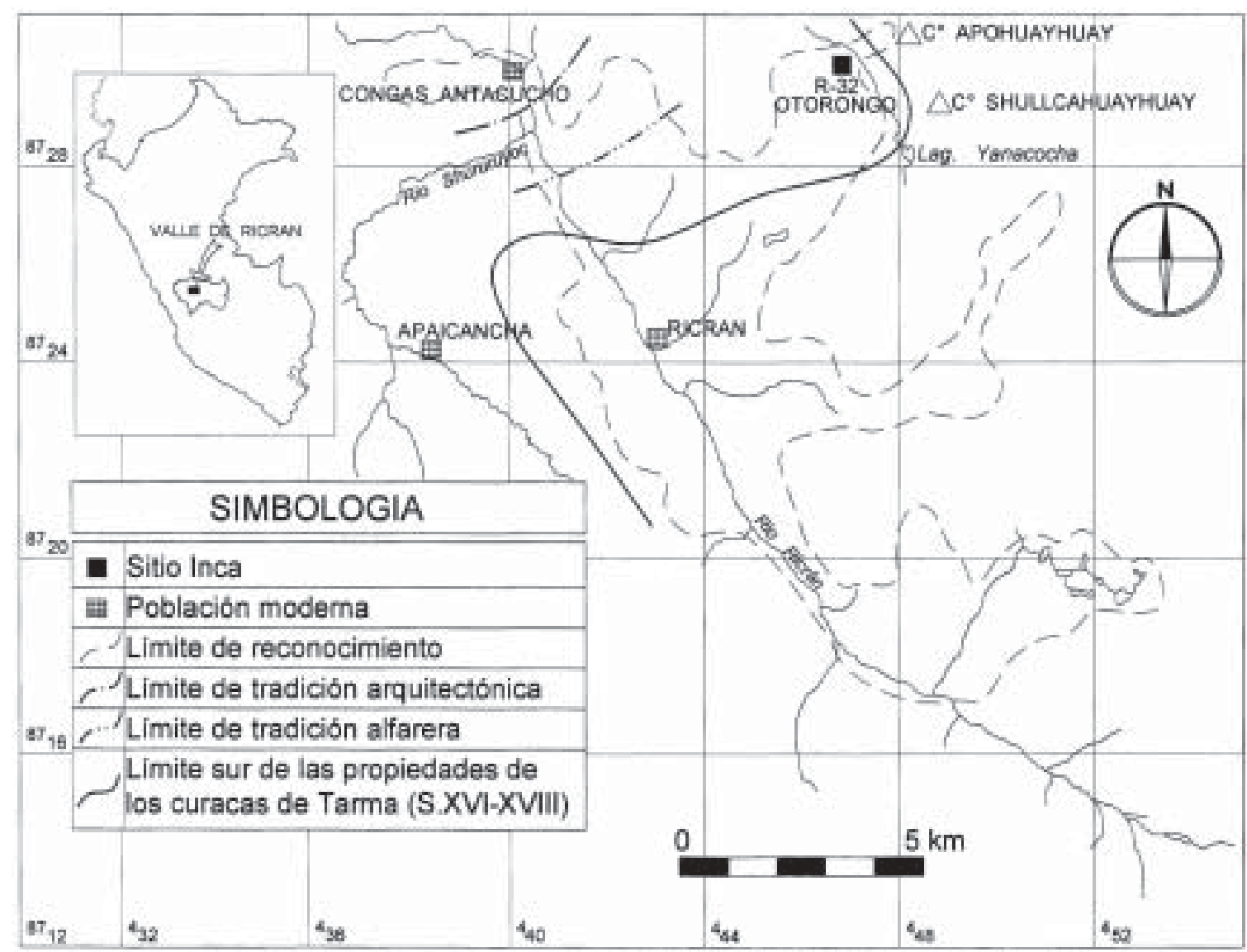

Figura 3. Localización de la posible zona de frontera Xauxa-Tarama (con información basada en Arellano 1988).

R-29 y R-35). Es también interesante que hacia esta parte se hayan identificado los límites meridionales de las haciendas que se hallaban bajo la jurisdicción de los curacas de Tarma hasta el siglo XVIII (Arellano 1988) y que llegaban hasta la montaña de Apohuayhuay, a la cual se le puede identificar con "Guayoay vilca, guaca prencipal de los taramas..." (Albornoz 1967 [1582]), ${ }^{7}$ en una clara manifestación de la naturaleza de las divinidades andinas como símbolos de frontera (Fioravanti 1986-87).

\section{Evidencias arqueológicas de los incas en el alto Ricrán}

Hasta el momento no hemos identificado sitio alguno que pueda ser clasificado como centro ad-

7 Esta relación entre Guayoay vilca y la montaña de Apohuayhuay fue propuesta antes por Hastings (1985: 194) y tomada en cuenta por Arellano (1988). ministrativo inca en el alto Ricrán. Sin embargo, es importante destacar la distribución diferencial de restos de cultura material inca en varios asentamientos locales, así como claros indicios de ciertos cambios en la configuración interna de algunos sitios.

Edificios de concepción arquitectónica inca en asentamientos locales

En la sección central más elevada de algunos asentamientos se pueden observar edificios de planta rectangular que claramente no corresponden al patrón arquitectónico local. Este es el caso de los sitios R-7 y R-17. En el primero, hemos identificado hacia su parte central una estructura rectangular de poco más de $15 \mathrm{~m}$ de largo y $5 \mathrm{~m}$ de ancho con una subdivisión interna, cuyos muros presentan un espesor promedio de $60 \mathrm{~cm} \mathrm{y}$ fueron levantados con una doble hilera de piedras asentadas en argamasa de barro. Debido a su avan- 
zado estado de destrucción a consecuencia de la agricultura moderna, no se distinguen de modo claro los vanos de acceso, aunque todo indica que, en número de dos, éstos se hallaban hacia el lado noreste del edificio.

En el sitio R-17 registramos otro edificio rectangular de piedra y barro, con muros de $60 \mathrm{~cm}$ de espesor, localizado hacia la parte más elevada del asentamiento. Mide $15 \mathrm{~m}$ de largo y casi $6 \mathrm{~m}$ de ancho, y presenta una orientación de noroeste a sureste y dos vanos de acceso hacia su lado occidental, los mismos que en su base cuentan con $1 \mathrm{~m}$ de ancho. En este caso resulta claro que para levantar este edificio o incorporarlo al grupo de patio donde se halla, se tuvo que desmontar una estructura circular adyacente (Figura 4).

Adicionalmente en los sitios R-14, R-20 y R-27 también se han identificado edificios rectangulares con muros y esquinas un tanto más irregulares y de dimensiones menores que los dos ejemplos anteriormente citados. En vista que tampoco corresponden a la tradición arquitectónica local, dejamos asimismo abierta la posibilidad de su correspondencia al Horizonte Tardío.

\section{Cerámica estatal en asentamientos locales}

En las colecciones de superficie procedentes de los sitios R-10, R-11 y R-35 se ha observado cerámica de factura estatal que, por sus características, puede ser clasificada como Inca local e Inca provincial (D'Altroy 1981, 1992, 2001b; Matos 1999). ${ }^{8}$ Esta cerámica se diferencia de la alfarería local en sus formas, decoración y acabado externo como en su mayor calidad tecnológica, pues su pasta es bastante fina, con pocas o casi imperceptibles partículas de temperante, además de presentar buena cocción y superficies pulidas, muchas veces cubiertas por un engobe típico de color rojo ocre. Aunque todavía no hemos realizado análisis cuantitativos y cualitativos más profundos, podemos adelantar que las formas representadas en las colecciones son en su mayoría jarros o aríbalos y platos.

\footnotetext{
8 Es principalmente D'Altroy (2001b: 248) quien establece estas distinciones para la región del Mantaro de acuerdo a la calidad del acabado de la alfarería, donde la clase Inca provincial o Xauxa Inca representa a piezas hechas provincialmente en el estilo Cusco, a diferencia de la cerámica Inca local que es de menor calidad.
}

\section{Instalaciones especiales}

En esta categoría estamos considerando al sitio R32 , Otorongo, que por sus características y su ubicación en asociación directa con la montaña de Apohuayhuay, podría haber cumplido alguna función ceremonial (Perales 2003 Ms-b). Se localiza en el margen izquierdo del río Opamayo, a 4060 m.snm y ocupa el fondo de una quebrada amplia, hacia la base de un farellón de roca calcárea.

El sitio consiste en un conjunto de terrazas artificiales sobre las que se observan muros rectos de piedra y barro que restringen la circulación y el acceso a su sector oriental donde se levantan dos estructuras de planta rectangular y una circular. Uno de los edificios rectangulares es relativamente grande, con $18.8 \mathrm{~m}$ de largo, $6 \mathrm{~m}$ de ancho y un azimut de $66^{\circ}$. En el muro norte se observa un vano de acceso de forma trapezoidal de $85 \mathrm{~cm}$ de ancho hacia su base. Debido a las pésimas condiciones de conservación del resto del muro, se ignora con precisión el número de vanos adicionales. Por su parte, el segundo edificio rectangular, ubicado a $6 \mathrm{~m}$ al noroeste del anterior, es mucho más pequeño que éste, con $4.4 \mathrm{~m}$ de largo, $2.80 \mathrm{~m}$ de ancho y un azimut de $60^{\circ}$. En ambos casos los muros presentan doble hilera de piedras y un espesor promedio de $60 \mathrm{~cm}$. En cuanto a la estructura circular, de $4 \mathrm{~m}$ de diámetro, hay que indicar que ésta ha sido reducida casi al nivel de sus bases debido al impacto de la actividad de pastoreo que se lleva a cabo actualmente (Figura 5).

Es necesario señalar que, pese a nuestros esfuerzos, no se pudo colectar material alfarero diagnóstico asociado al sitio, lo cual dificulta su ubicación cronológica certera. Sin embargo, si tomamos en cuenta las características de la arquitectura y planificación de los edificios rectangulares descritos, es muy posible que correspondan a cánones inca (Gasparini y Margolies 1977; Kendall 1976; Hyslop 1990). ${ }^{9}$

\footnotetext{
9 Aquí nos referimos principalmente a características como el tipo de planta (rectangular), disposición espacial, dimensiones de los edificios, espesor de los muros (mucho mayor al espesor promedio de los muros de los edificios de tradición local) y la presencia de al menos un vano de acceso trapezoidal. A ello podemos agregar la orientación de la estructura rectangular mayor que seguiría un alineamiento solsticial (Perales 2003 Ms-b).
} 


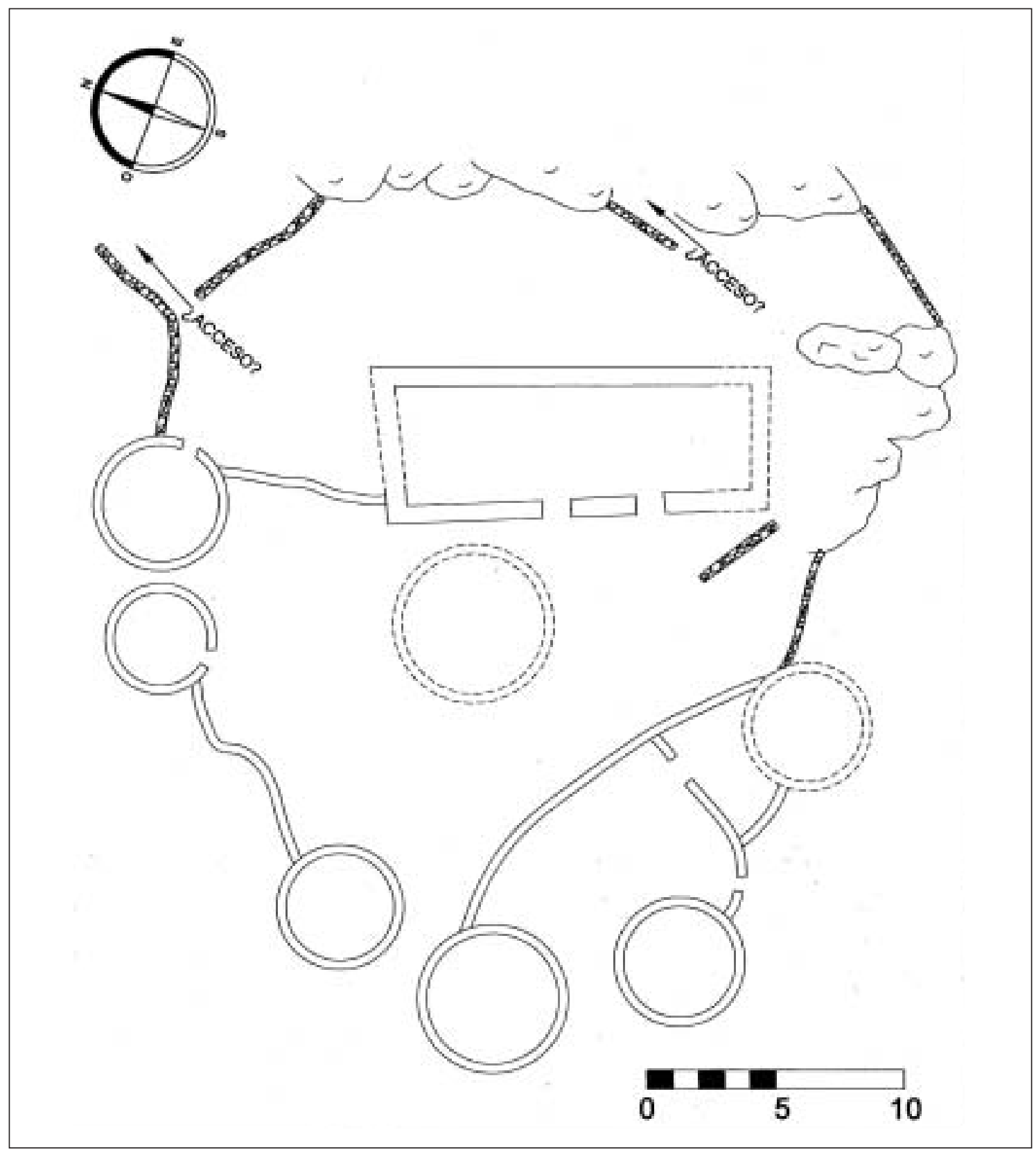

Figura 4. Estructura rectangular de posible inspiración inca en el sitio R-17, Pariamarca.

\section{El impacto de la presencia inca en las sociedades tardías del alto Ricrán}

Debido a su localización geográfica, el valle de Ricrán se hallaba fuera del ámbito de influencia directa del eje troncal serrano del Qhapaqñan que unía Cusco con Quito, el cual pasaba por los centros provinciales de Pumpu, Tarmatambo ${ }^{10}$ y Hatun Xauxa. Sin embargo, ello no mermó en la importancia que debió tener Ricrán para el Estado inca por su significativo potencial productivo agropecuario y su proximidad a la ceja de selva de Monobamba y a montañas sagradas

10 Esta instalación inca, de menor rango que Hatun Xauxa, viene siendo objeto de estudio en los últimos años por parte de Ramiro Matos, Carmen Arellano y David Brown (Matos et al. 1996; Matos 1997, 2002; Brown 1998). 


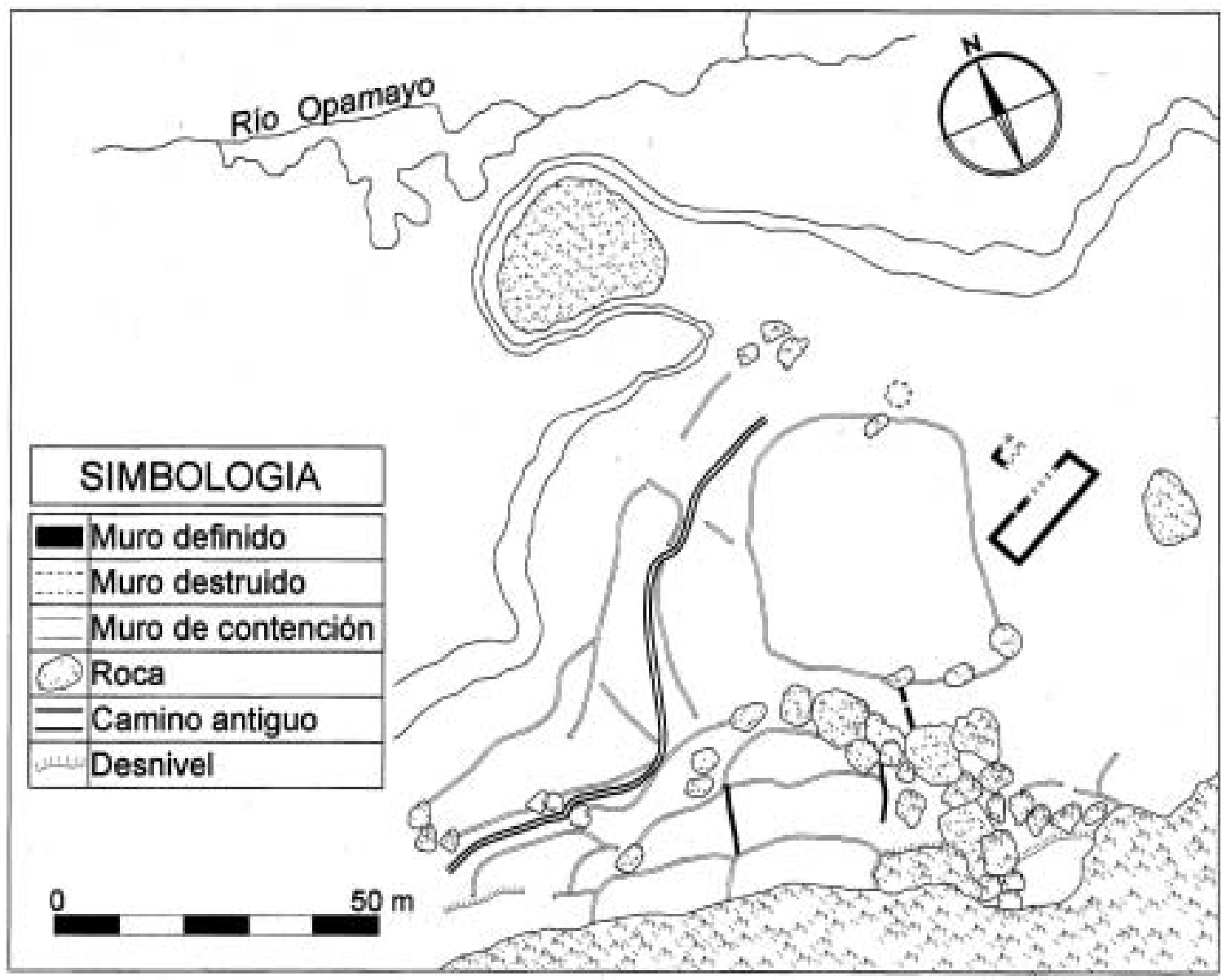

Figura 5. Plano preliminar del sitio R-32, Otorongo.

como el Apohuayhuay. A continuación comentaremos algunos cambios que habrían ocurrido en el alto Ricrán a consecuencia de su eventual incorporación al Tawantinsuyu, siempre con las precauciones del caso debido a los problemas de orden cronológico de los cuales adolece nuestro registro.

Patrón de asentamiento y arquitectura

En diferentes partes de la sierra central del Perú se ha detectado una tendencia hacia la reubicación de los asentamientos locales en puntos más bajos y cercanos al fondo de los valles durante el Horizonte Tardío (D’Altroy 1992; Parsons 1998), con el consiguiente abandono de varios de los sitios emplazados en el piso puna. Ello todavía no es del todo contrastable en el alto Ricrán, debido a la carencia de datos de excavación y a que en la mayoría de los sitios las colecciones de superficie muestran una recurrencia constante de tipos alfareros como Mantaro Base Clara, cuya producción, según otros autores (Costin 1986), habría continuado en tiempos del dominio incaico.

No obstante, existen algunos elementos de juicio que nos permiten postular la posibilidad de la ocupación o reocupación de la mayoría de los sitios catalogados como asentamientos de agricultores durante el Horizonte Tardío. Ellos son:

1) Ausencia de elementos arquitectónicos de posible carácter "defensivo" (muros perimétricos y zanjas) en casi todos los asentamientos de agricultores. La única excepción al respecto sería el sitio R-11 que exhibe una zanja hacia su extremo suroeste.

2) Presencia de alfarería inca en mayor cantidad en asentamientos de agricultores como los sitios R-10 y R-11, a lo cual debemos agregar que en otros casos también hay presencia de edificios de 
muy posible inspiración inca en estos asentamientos, como es el caso del sitio R-7.

3) Presencia de alfarería inca, aunque muy dispersa y escasa, en algunos conjuntos de terrazas agrícolas asociadas a los asentamientos de agricultores, hecho que no se ha observado en los corrales anexos a los asentamientos de ganaderos.

Esta probable reubicación de las poblaciones del alto Ricrán hacia altitudes inferiores podría implicar el abandono de los asentamientos de ganaderos que, como ya vimos antes, encabezaban la jerarquía local de asentamientos durante el Intermedio Tardío. Sin embargo, nos preguntamos si esto sucedió en todos los casos, pues contamos con sitios en el piso puna que exhiben cerámica estatal (sitio R-35) y edificios de concepción arquitectónica inca asociados a eventos de reorganización de espacios (sitio R-17). Pese a estos cambios durante el dominio inca, los grupos de patio continuaron siendo las unidades arquitectónicas básicas, aunque con sutiles alteraciones en sus dimensiones y grado de variabilidad, a la par de una notoria disminución en su densidad como ocurre en los asentamientos de agricultores, donde también se observa una reducción notoria en la calidad del acabado de las caras externas de los muros de las estructuras. Fenómenos similares se han observado en la región de Jauja (DeMarrais 2001).

Distinciones de prestigio a nivel local

La continuidad en el uso de los grupos de patio como unidades residenciales durante el Horizonte Tardío estaría indicando la persistencia de ciertas formas de organización social en el nivel doméstico en tiempos del dominio inca, aunque también se cuentan con indicios de ciertas transformaciones reflejadas en sutiles cambios en la configuración de los grupos de patio (Earle et al. 1987; DeMarrais 2001).

Así, en el alto Ricrán se distingue un incremento en las dimensiones de los edificios y en la extensión de los grupos de patio en los asentamientos de agricultores, aspectos que pudieron ser consecuencia de la necesidad de mayor espacio para desarrollar actividades relacionadas con la producción para el Estado inca (p.e., producción de chicha) o también producto de una mejor disponibilidad de áreas libres por el emplazamiento de es- tos sitios en zonas menos agrestes (DeMarrais 2001). De igual modo, el poco énfasis puesto en un posible marcador de estatus durante el Intermedio Tardío como es la calidad de la albañilería externa de los edificios en los asentamientos de agricultores podría indicar el abandono de ciertos símbolos tradicionales de diferenciación social a raíz de la incorporación de nuevos elementos de inspiración inca, como el uso de viviendas de planta rectangular y de vajilla de factura estatal. Cabe mencionar que cambios de esta naturaleza también se han reportado previamente en Jauja (D’Altroy 2001b; DeMarrais 2001), Huánuco (Morris y Thompson 1985; Grosboll 1993) y Ayacucho (Schreiber 1993), por ejemplo.

En su conjunto, los datos sugieren un clima de cambios en la configuración social y quizá política de las poblaciones locales del alto Ricrán en tiempos del Tawantinsuyu, donde ciertos segmentos de la élite local se habrían incorporado al aparato estatal, ejerciendo nuevas posiciones de autoridad que se exteriorizaron con el uso de símbolos vinculados al régimen del Cusco. En este contexto, la presencia de espacios públicos en algunos asentamientos de agricultores como el sitio R-11 sería un indicio del desarrollo de actividades públicas más formalizadas en las cuales la élite local habría jugado roles protagónicos con el aval del Estado. ${ }^{11}$

\section{Ricrán en el contexto regional}

De acuerdo a las fuentes documentales que estamos manejando (Espinoza 1971, 1973; Vega 1881 [1582]; Arellano 1988), la cuenca alta del río Ricrán durante el régimen inca habría sido incluida dentro de la jurisdicción administrativa del centro provincial de Hatun Xauxa, aunque también es posible que haya mantenido vínculos con instalaciones estatales localizadas hacia Tarma.

En el alto Ricrán, las grandes extensiones de laderas habilitadas para la agricultura mediante la construcción de terrazas de cultivo que se hallan

11 Prueba de ello sería la presencia de jarros y platos inca en los denominados "asentamientos de agricultores" como el sitio R-11. Estas ceremonias o actividades públicas debieron darse en el marco de una hospitalidad ritual de profunda raíz en los Andes, donde ciertos segmentos de la élite local estarían renovando sus vínculos con el gobierno del Cusco. 
asociadas a los asentamientos de agricultores, y que exhiben algunos restos de alfarería inca en superficie, sugieren algún tipo de proceso de intensificación de la agricultura en tiempos del Tawantinsuyu como parte de programas dirigidos por el Estado, ${ }^{12}$ que contemplaron, además, la reubicación de varias comunidades originalmente instaladas hacia la puna en puntos más bajos y cercanos a estos campos de cultivo. La inexistencia de centros de almacenaje estatal en el alto Ricrán obliga a pensar en el traslado de los bienes producidos en esta zona hacia centros provinciales como Hatun Xauxa y Tarmatambo, ${ }^{13}$ mediante caminos reacondicionados o preparados por los incas cuyos vestigios podrían ser los segmentos de vías empedradas que se observan en las quebradas de Cachirumi, camino a Jauja y en las alturas de la cordillera de Apohuayhuay que según los lugareños unía Ricrán con Tarma y la ceja de selva de Monobamba. Ello, sumado a la posición estratégica del valle de Ricrán entre los bosques tropicales de la cuenca del Tulumayo y los valles interandinos de Tarma y el Mantaro, convirtieron a este territorio en una zona de tráfico significativo de bienes que habrían abastecido al menos los depósitos estatales de Hatun Xauxa y Tarmatambo. En estas actividades oficiales la labor administrativa cumplida por sectores de la élite

12 Hastorf y Earle (1985) han analizado las relaciones entre la implementación de infraestructura agrícola (canales de irrigación, terrazas de cultivo) y los procesos de intensificación de la agricultura en el valle de Yanamarca, Jauja, desde el Intermedio Temprano hasta el Horizonte Tardío. Al respecto, las terrazas agrícolas del alto Ricrán corresponden al tipo llamado "andenes rústicos" (sin muros de contención de piedra) por estos autores, quienes señalan que su construcción no requería de una labor corporativa importante. Por ello pensamos que, si bien muchas de estas terrazas pudieron ser preparadas desde el Intermedio Tardío o quizás antes, la presencia de cerámica inca en algunas de ellas y la posible reubicación de las poblaciones locales hacia el valle sugieren un interés por parte del Estado inca en la intensificación de la explotación agrícola de la zona.

13 Quisiéramos indicar también que tras un rápido análisis de pastas de fragmentos inca del alto Ricrán y de Tarmatambo, encontramos similitudes entre varios de ellos. $\mathrm{Al}$ respecto se ha señalado que, aunque existen ciertas diferencias en la composición de las arcillas de cerámica inca del valle de Yanamarca, Tarmatambo y el alto Ricrán (Costin 2001: 233), hay cierta similitud composicional entre las muestras de Hatun Xauxa y Tarmatambo (D'Altroy 2001b). Análisis más profundos de la cerámica inca del alto Ricrán podrían ayudar a esclarecer los vínculos entre los conjuntos alfareros inca de las regiones de Jauja y Tarma. local incorporada al aparato de gobierno seguramente fue importante.

Además de esta importancia, el alto Ricrán era el espacio que albergaba a una de las divinidades más importantes de toda la región, Guayoay vilca, huaca que marcaba una zona de doble frontera: la primera entre poblaciones vinculadas a entidades étnicas diferentes, Xauxa y Tarama, y la segunda entre la sierra y la floresta tropical amazónica de gran importancia simbólica para las sociedades andinas. ${ }^{14}$ Como hemos propuesto en otra ocasión (Perales 2003 Ms-b), tanto el control de esta zona de frontera que mira al Antisuyu y que cuenta con una connotación de transición espacial y temporal vinculada al símbolo del felino u otorongo (Fioravanti 1986-87) ${ }^{15}$ así como la incorporación de Guayoay vilca al panteón oficial del Estado, habrían facilitado a los incas un mejor ejercicio del poder sobre las sociedades locales. Por ello, es fundamental corroborar la filiación inca del sitio R-32, asociado directamente con la montaña de Apohuayhuay.

\section{Comentarios finales}

Pese a que las ideas esbozadas en esta ocasión se basan en datos de superficie, consideramos que pueden contribuir en la definición de una agenda de investigación sobre el carácter de la presencia inca en los pequeños valles periféricos de la sierra central peruana.

Partiendo del estudio de los patrones de asentamiento locales y de un seguimiento cuidadoso de la distribución de los restos materiales inca en el alto Ricrán, podríamos adelantar a modo de hipótesis que en esta región durante el Horizonte Tardío ocurrió una reubicación de ciertos sectores de la población hacia puntos más bajos, como parte de políticas estatales orientadas a intensificar la producción agrícola mediante la habilitación de grandes extensiones de terrazas de cultivo en las laderas del valle. Debido a la ausencia de infra-

14 Guamán Poma (1987 [1615]: 268) proporciona valiosa información sobre el punto al referirse a las huacas del Antisuyu como Sawasiray y Pitusiray en el Cusco, las cuales son mostradas en directa asociación con el símbolo del jaguar u otorongo.

15 Al respecto, Zuidema (1989) es uno de los autores que ha trabajado con mayor profundidad sobre el sentido de transición que tuvo el símbolo del felino en el Tawantinsuyu. 
estructura de almacenaje estatal en Ricrán pensamos que casi toda esta producción, sumada a los bienes procedentes de la ceja de selva de Monobamba, se estaría concentrando en los centros provinciales más inmediatos como Hatun Xauxa y Tarmatambo mediante caminos habilitados para tal fin. En este contexto, fue fundamental la participación de determinadas facciones de la élite local como parte de la burocracia del Estado en las labores de administración de los tributos y en la coordinación de actividades dirigidas y auspiciadas por el régimen inca. Los miembros de estos segmentos de élite, seguramente con la venia del Estado, habrían empleado símbolos oficiales como viviendas de planta rectangular y cerámica estatal con la finalidad de afianzar sus posiciones de autoridad ante los ojos de sus comunidades. No se descartan, a todo esto, ciertas formas de coerción o dominio ideológico a través de la "conquista" de la huaca Guayoay vilca por parte de los incas y de su incorporación al panteón oficial. ${ }^{16}$ Además, la eventual zona de frontera que estaríamos identificando entre poblaciones de aparente filiación étnica distinta también debió ser aprovechada desde el punto de vista político, con la finalidad de manipular las tensiones existentes entre los grupos vecinos en provecho propio (Morris 1998) y para mantener una posición más neutral ante éstos tal como se ha sugerido para algunas zonas vecinas (Parsons et al. 2000: 138-139).
Antes de concluir con el presente trabajo, queremos recalcar nuevamente su carácter preliminar, por cuanto sólo hemos intentado resumir las ideas e hipótesis que orientarán futuras temporadas de investigación en el alto Ricrán. Estas contribuirán a una mejor comprensión de las estrategias de dominio inca en las zonas adyacentes a los bosques nublados de la ceja de selva en esta parte de la sierra central peruana.

Agradecimientos Nuestras investigaciones en el alto Ricrán fueron financiadas por la Municipalidad Distrital de Ricrán y contaron con la autorización del Instituto Nacional de Cultura (ref. RDN $n^{\circ}$ 918/INC) y los auspicios del Centro de Estudios "Julio Espejo Núñez" de Jauja y el Instituto del Bien Común de Lima, a los cuales expresamos nuestra gratitud. Debemos agradecer igualmente a Carmen Arellano, Ramiro Matos, David Browman, Charles Hastings y Richard Smith por sus valiosas críticas y comentarios sobre el presente trabajo, así como a José Pino y Hugo Marroquín por su invalorable apoyo espiritual, material y logístico. Finalmente deseamos reconocer a los miembros del Proyecto Arqueológico Ricrán, Rosendo Rodríguez, Mario Advíncula, Agustín Rodríguez, Katty Mosquera, Santiago Rivas, Anderson Chamorro, Arturo Noel, Brener Meza y Jackeline Nunura, por su esfuerzo desplegado durante las duras jornadas de campo.

\section{REFERENCIAS CITADAS}

ALBORNOZ, C., 1967 [1582]. La instrucción para descubrir todas las guacas del Pirú y sus camayos y haciendas. Journal de la Societé des Americanistes 56: 9-39.

ARELLANO, C., 1988. Apuntes históricos sobre la provincia de Tarma en la sierra central del Perú. BAS Series, $\mathrm{n}^{\mathrm{o}} 15$, Bonn.

BONNIER, E., 1997. Morfología del espacio aldeano y su expresión cultural en los Andes Centrales. En Archaelogica Peruana 2, E. Bonnier y H. Bischof (Eds.), pp. 28-41. Sociedad Arqueológica Peruano-Alemana / Reiss-Museum, Mannheim.

BROWMAN, D., 1970. Early peruvian peasants: The culture history of a central highlands valley. Ph. D. Dissertation,

16 Pachacuti Yamqui (1995 [1613]) es bastante explícito cuando habla del carácter religioso de la expansión incaica en la que era fundamental la captura de las huacas regionales.
Departament of Anthropology, Harvard University, Cambridge.

BROWN, D., 1998. Water and power in the provinces: Water management in inca centers of central highlands of Peru. Tawantinsuyu 5: 23-36.

CIEZA DE LEON, P. 1946 [1553]. La Crónica General del Perú. En Crónicas de la conquista del Perú, J. De Riverend (Ed.), pp. 125-497. Editorial Nueva España, México D. F.

COSTIN, C., 1986. From chiefdom to Empire State: Ceramic economy among the prehispanic wanka of Highland Peru. $\mathrm{Ph}$. D. Dissertation, University of California at Los Angeles, Los Angeles.

_-1986-87. Cerámica prehispánica tardía del valle de Yanamarca, Junín. Revista del Museo Nacional 48: 195-211.

2001. Production and exchange of ceramics. En Empire and domestic economy, T. D'Altroy y C. Hastorf (Eds.), 
pp. 203-242. Kluwer Academic / Plenum Publishers, Nueva York.

D'ALTROY, T., 1981. Empire growth and consolidation: The Xauxa region of Peru under the incas. Doctoral Dissertation, Department of Anthropology, University of California, Los Angeles.

1992. Provincial power in the Inca Empire. Smithsonian Institution Press, Washington y Londres.

-2001a. The cultural setting. En Empire and domestic economy, T. D'Altroy y C. Hastorf (Eds.), pp. 27-53. Kluwer Academic / Plenum Publishers, Nueva York.

2001b. State goods in the domestic economy: The inca ceramic assemblage. En Empire and domestic economy, T. D'Altroy y C. Hastorf (Eds.), pp. 243-264. Kluwer Academic / Plenum Publishers, Nueva York.

DEMARRAIS, E., 2001. The architecture and organization of Xauxa settlements, En Empire and domestic economy, T. D'Altroy y C. Hastorf (Eds.), pp. 115-153. Kluwer Academic / Plenum Publishers, Nueva York.

EARle, T., T. D'Altroy, C. HAStORF, C. SCOTT, C. COSTIN, G. RUSSELL y E. SANDEFUR, 1987. Archaeological field research in the Upper Mantaro valley, Peru: 1982-1983. Investigations of Inca expansion and exchange. Monograph 28, Institute of Archaeology, University of California, Los Angeles.

EARLE, T., T. D'ALTROY, C. SCOTT, C. HASTORF y T. LEVINE, 1988. Sobre la penetración inca en el valle del Mantaro. Boletín de Lima 59: 39-50.

ESPINOZA, W., 1971. Los Huancas, aliados de la conquista. Anales Científicos de la Universidad del Centro del Perú 1: 3-407.

1973. Historia del departamento de Junín. En Enciclopedia Departamental de Junín, E. Chipoco (Ed.), T I: 9395. Editorial San Fernando, Huancayo.

ESTETE, M., 1946 [1533]. La relación del viaje que hizo el Señor Capitán Hernando Pizarro por mandado del señor gobernador, su hermano, desde el pueblo de Caxamalca a Parcama y de allí a Jauja. En Crónicas de la conquista del Perú, J. De Riverend (Ed.), pp. 90-108. Editorial Nueva España, México D. F.

FIORAVANTI, A., 1986-1987. El simbolismo de frontera en los Andes. Revista del Museo Nacional 48: 251-286.

GASPARINI, G. y L. MARGOLIES, 1977. Arquitectura inca. Centro de Investigaciones Históricas y Estéticas, Facultad de Arquitectura y Urbanismo, Universidad Central de Venezuela, Caracas.

GROSBOLL, S., 1993. And he said in the time of the Ynga, they paid tribute and served the Ynga. En Provincial inca, M. Malpass (Ed.), pp. 44-76. University of Iowa Press, Iowa City.
GUAMAN POMA DE AYALA, F., 1987 [1615]. Nueva crónica y buen gobierno, J. Murra, R. Adorno y J. Urioste (Eds.). Editorial Siglo XXI, México D. F.

HASTINGS, C., 1985. The eastern frontier: Settlement and subsistence in the Andean margins of Central Peru. Doctoral Dissertation, Department of Anthropology. University of Michigan, Ann Arbor.

-1987. Implications of Andean verticality in the evolution of political complexity: A view from the margins. En The origins and development of the Andean State, J. Haas, S. Pozorski y T. Pozorski (Eds.), pp. 145-157. Cambridge University Press, Cambridge.

HASTORF, C., 2001. Agricultural production and consumption. En Empire and domestic economy, T. D'Altroy y C. Hastorf (Eds.), pp. 155-178. Kluwer Academic / Plenum Publishers, Nueva York.

HASTORF, C. y T. EARLE, 1985. Intensive agriculture and the geography of political change in the Upper Mantaro region of central Peru. En Prehistoric intensive agriculture in the tropics, I. Farrington (Ed.), pp. 559-597. BAR Series, Oxford.

HASTORF, C., T. EARLE, H. WRIGHT, L. LECOUNT, G. RUSSELL y E. SANDEFUR, 1989. Settlement archaeology in the Jauja region of Peru. Evidence from the Early Intermediate Period through the Late Intermediate Period. A report on the 1986 field season. Andean Past 2: 81-129.

HYSLOP, J., 1990. Inca settlement planning. University of Texas Press, Austin.

KENDALL, A., 1976. Descripción e inventario de las formas arquitectónicas inca. Revista del Museo Nacional 42: 13-96.

LAVALLEE, D., 1967. Types ceramiques des Andes Centrales du Perou (Periode Intermediaire Récente). Journal de la Societé des Americanistes 56: 323-364.

LAVALlEE, D. y M. JULIEN, 1983. Asto: Curacazgo prehispánico de los Andes Centrales. Instituto de Estudios Peruanos, Lima.

LEBLANC, C., 1981. Late Prehispanic Huanca settlement patterns in the Yanamarca valley, Peru. Doctoral Dissertation, Department of Anthropology. University of California, Los Angeles.

LEVINE, T., 1985. Inca administration in the Central Highlands: A comparative study. Doctoral Disseration, Department of Anthropology, University of California, Los Angeles.

LUMBRERAS, L., 1957. La Cultura Wanka. Ondas Isabelinas 1: $15-18$.

1960. Esquema arqueológico de la sierra central del Perú. Revista del Museo Nacional 28: 64-117. 
MATOS, R., 1959. Los Wanka: Datos históricos y arqueológicos. Actas y Trabajos del II Congreso Nacional de Historia del Perú: Epoca Prehispánica, T II: 187-210. Lima.

-1994. Pumpu. Centro administrativo inca de la puna de Junin. Editorial Horizonte, Lima.

_ 1997. Incas y etnias regionales en Junín. Una visión arqueológica. En Arqueología, antropología e historia en los Andes. Homenaje a María Rostworowski, R. Varón y J. Flores (Eds.), pp. 397-413. Instituto de Estudios Peruanos / Banco Central de Reserva, Lima.

1999. La cerámica inca. En Los incas. Arte y símbolos, Colección Arte y Tesoros del Perú, pp. 109-165. Banco de Crédito del Perú, Lima.

2002. El awana wasi de Tarmatambo: Una aproximación etnoarqueológica. En El hombre y los Andes. Homenaje a Franklin Pease G. Y., J. Flores y R. Varón (Eds.), T I: 679-694. Pontificia Universidad Católica del Perú, Fondo Editorial, Lima.

MATOS, R., C. ARELLANO y D. BROWN, 1996. Asentamientos inca en Chakamarka y Tarmatambo (departamento de Junín): Problemas y criterios de interpretación para la reconstrucción de una provincia inca. En I Encuentro Internacional de Peruanistas, T I: 181-190. UNESCO / Universidad de Lima / Fondo de Cultura Económica, Lima.

MORRIS, C., 1998. Inca strategies of incorporation and governance. En Archaic states, G. Feinman y J. Marcus (Eds.), pp. 293-309. School of American Research, Santa Fe, Nuevo México.

MORRIS, C. y D. THOMPSON, 1985. Huanuco Pampa: An inca city and its hinterland. Thames and Hudson, Londres.

PARSONS, J., 1998. A regional perspective on inca impact in the sierra central, Peru. Tawantinsuyu 5: 153-159.

PARSONS, J., C. HASTINGS y R. MATOS, 1997. Rebuilding the State in Highland Peru: Herder-cultivator interaction during the Late Intermediate Period in the TaramaChinchaycocha Region. Latin American Antiquity 8 (4): 317-341.

2000. Prehispanic settlement patterns in the Upper Mantaro and Tarma drainages, Junin, Peru. Vol. I. The
Tarama-Chinchaycocha Region. Memoirs of the Museum of Anthropology 34, University of Michigan, Ann Arbor.

PACHACUTI YAMQUI, J., 1995 [1613]. Relación de antigüedades de este Reino del Perú, C. Araníbar (Ed.). Fondo de Cultura Económica, Lima.

PERALES, M., 2003 Ms-a. Una propuesta para la reconstrucción del mosaico étnico prehispánico tardío en la sierra central del Perú. Manuscrito en poder del autor.

-2003 Ms-b. El control inca de las fronteras étnicas: Reflexiones desde el valle de Ricrán en la sierra central del Perú. Manuscrito en poder del autor.

2004. Ancestros y muerte en las sociedades prehispánicas tardías del alto Ricrán, sierra central del Perú: Una aproximación arqueológica. En Imagen de la muerte. Primer Congreso Latinoamericano de Ciencias Sociales y $\mathrm{Hu}$ manidades, N. Leonardini, D. Rodríguez y V. Cabanillas (Comps.), pp. 49-57. Universidad Nacional Mayor de San Marcos, Lima.

PERALES, M. y A. RODRIGUEZ, 2003. Asentamientos prehispánicos tardíos en la puna de Chongos Bajo (Chupaca-Junín). Unay Runa 6: 55-59.

PULGAR, J., 1967. Geografía del Perú: Las ocho regiones naturales del Perú. Universidad Nacional Mayor de San Marcos, Lima.

SCHREIBER, K., 1993. The inca occupation of the province of Andamarca Lucanas, Perú. En Provincial inca, M. Malpass (Ed.), pp. 77-116. University of Iowa Press, Iowa City.

TOSI, J., 1960. Zonas de vida natural en el Perú. Instituto Interamericano de Ciencias Agrícolas de la OEA, Zona Andina, Proyecto 39. Programa de Cooperación Técnica, Boletín 5, Lima.

VEGA, A., 1881 [1582]. La descripción que se hizo en la provincia de Xauxa por la instrucción de Su Majestad que a la dicha provincia se envió de molde. En Relaciones Geográficas de Indias, T I: 79-95. Ministerio de Fomento del Perú, Madrid.

ZUIDEMA, T., 1989. El león en la ciudad. Símbolos reales de transición en el Cusco. En Reyes y guerreros. Ensayos de Cultura Andina, M. Burga (Comp.), pp. 306-383. Fomciencias, Lima. 